\title{
The Impact Of Entry At A Distance On Market Demand
}

\author{
Bruce L. Benson*
}

A number of recent papers have noted that the pricing implications of the most commonly used "Löschian" model of spatial competition are "counterintuitive" and therefore "perverse" $[6,7,8,11] .{ }^{1}$ It turns out that the intuitive expectations of these writers were based on an incorrect presumption-that spatial competition should duplicate the results of spaceless competition. However, the introduction of costly distance causes adjustments which we do not ordinarily consider in spaceless competition.

All of the so-called perverse conclusions of the Löschian model occurred as a result of the impact of entry or exit on price [2]. It was found that entry leads to higher prices in Löschian spatial competition $[6,7,8,11]$. The intuitive argument which makes this result perverse is that entry into a non-spatial competitive market shifts the supply curve out and price falls. Therefore, entry into a spatial market should also cause price to fall. Indeed, entry in a spatial setting does increase supply (the number of firms). However, since more consumers are served and/or average transport costs are lowered, there also is an increase in demand. The price effect in spaceless competition is indeterminate when both demand and supply are increased unless we specify the nature of the supply and demand changes. The same is true in a spatial setting but a higher price is certainly possible. ${ }^{2}$ Occurrences which affect only supply or demand in a spaceless world affect both supply and demand in a spatial world. When we realize this, the conclusions of spatial competition are no longer so surprising.

The following discussion of the impact of entry (and exit) on market demand is presented because this is the crucial relationship which provides us with an "intuitive" justification for what have been called the "perverse" results of some models of spatial competition. This is done in order to demonstrate that the results are not perverse-that is, spaceless competition yields the same results when market demand is a function of the number of competitors.

The essential feature of spatial competition is transportation cost. As Greenhut noted, spaceless perfect competition cannot occur when firms and consumers are geographically distributed and distance is costly [10]. This oc-

\footnotetext{
*Department of Economics, The Pennsylvania State University, University Park, PA 16802.
} 
curs because consumers pay the price charged by a firm plus the cost of transporting the product. Thus, aggregate as well as individual demand for a single homogeneous product can be defined as:

$$
P+t u=f(Q)=f(n q)
$$

where $\mathrm{Q}$ is aggregate demand, $\mathrm{q}$ stands for the individual demand for all $\mathrm{n}$ buyers, $P$ represents the firm's mill or gate price, $t$ is the transport rate per unit of distance (assumed constant), and $\mathrm{u}$ is units of distance from the nearest seller. ${ }^{3}$ Assume all consumers have identical demand functions and let potential consumers occupy a homogeneous linear space of uniform density D. Equation (1) can be rewritten as:

$$
q=\frac{1}{n} f^{-1}(P+t u)
$$

The relevant aggregate demand for a single f.o.b. pricing spatial monopolist selling in both directions from his location $\left(Q_{m}\right)$ is:

$$
Q_{m}(P)=\frac{2 D}{U} \int_{0}^{U} f^{-1}(P+t u) d u, d u=\frac{U}{n}, U=\frac{f(0)-P}{t}
$$

where $U$ is the distance to the monopolist's market boundary. Equation (3) is demand net of transport costs, or the effective demand to the firm. The firm's demand is the market demand, given a single spatial monopolist.

With entry in spaceless competition the supply side of the market changes but market demand is unaffected. This is not the case in spatial competition. Entry leads to an increase in market demand as well as altering supply conditions. In other words, market demand is a function of price and the number of firms dispersed over the space:

$$
\mathrm{Q}(\mathrm{P}, \mathrm{N})=\frac{2 \mathrm{ND}}{\mathrm{U}} \int_{0}^{\mathrm{U}^{\prime}} \mathrm{f}^{-1}(\mathrm{P}+\mathrm{tu}) \mathrm{du} .
$$

$\mathrm{N}$ denotes the number of firms while $\mathrm{U}^{\prime}$ represents the distance to a firm's service area boundary when the firm faces distant competition. This equation presumes firm sites are spaced evenly over the line market. ${ }^{4}$ In such case:

$$
\mathrm{U}^{\prime} \leq \mathrm{U}, \mathrm{U}^{\prime}=\frac{\mathrm{T}}{2 \mathrm{~N}},
$$

where $\mathrm{T}$ stands for an exogenously given total market size. This follows because the size of any one firm's sales area depends upon the number of other firms in the market space. 
The portion of total sales made by each firm $\left(\mathrm{S}=\frac{\mathrm{Q}}{\mathrm{N}}\right)$ accordingly is:

$$
\begin{aligned}
& S=\frac{2 D}{U} \int_{0}^{U^{\prime}} f^{-1}(P+t u) d u, \\
& S=S(P, N ; T) .
\end{aligned}
$$

Market demand is now a function of the number of firms dispersed over the space and the mill price charged by these firms. ${ }^{5}$ Thus:

$$
\mathrm{Q}=\mathrm{NS}(\mathrm{P}, \mathrm{N}) \text {, }
$$

and

$$
\begin{aligned}
& \frac{\partial Q}{\partial N}=S+N \frac{\partial S}{\partial N}=S+f^{-1}\left(P+t U^{\prime}\right)\left(-\frac{T}{N}\right), \\
& \frac{\partial Q}{\partial N}=S-2 U^{\prime} f^{-1}\left(P+t U^{\prime}\right) .
\end{aligned}
$$

As more firms are dispersed over the market space, effective demand increases (as in Figure 1). Actual changes in demand depend upon the parameters and exogenous variables of the market. However, intuition tells us that initially, when there are only a few plants, additional sites probably increase market demand by substantial amounts. Eventually, however, additional firms imply the market share going to existing firms must fall. That is, each firm may remain a monopolist for a while as a few firms enter at distant sites. At some point, however, firms should begin to compete at their sales area boundaries and $\mathrm{U}^{\prime}$ becomes increasingly smaller with continued entry. Thus, additional firms are expected to increase total demand by smaller and smaller amounts since existing firms lose some customers in the process. Market demand should continue to increase with entry even though each firm serves a smaller and smaller market. This results because, with entry at a distant point and spatial competition, existing consumers near the periphery of existing firm boundaries pay less in transport costs. Consequently, these consumers are able to obtain more goods for consumption at any level of income as less is spent on transportation services. If $\mathrm{N}=\infty$ one firm serves each point in space. Transport costs are no longer relevant and market demand is maximized. However, as long as $\mathrm{N}<\infty$ market demand should increase with entry of an additional firm.

An increase in price is not surprising in spaceless competition when both demand and supply shift out. In a spaceless setting supply is obviously a function of the number of firms but demand is not. However, in spatial competi- 


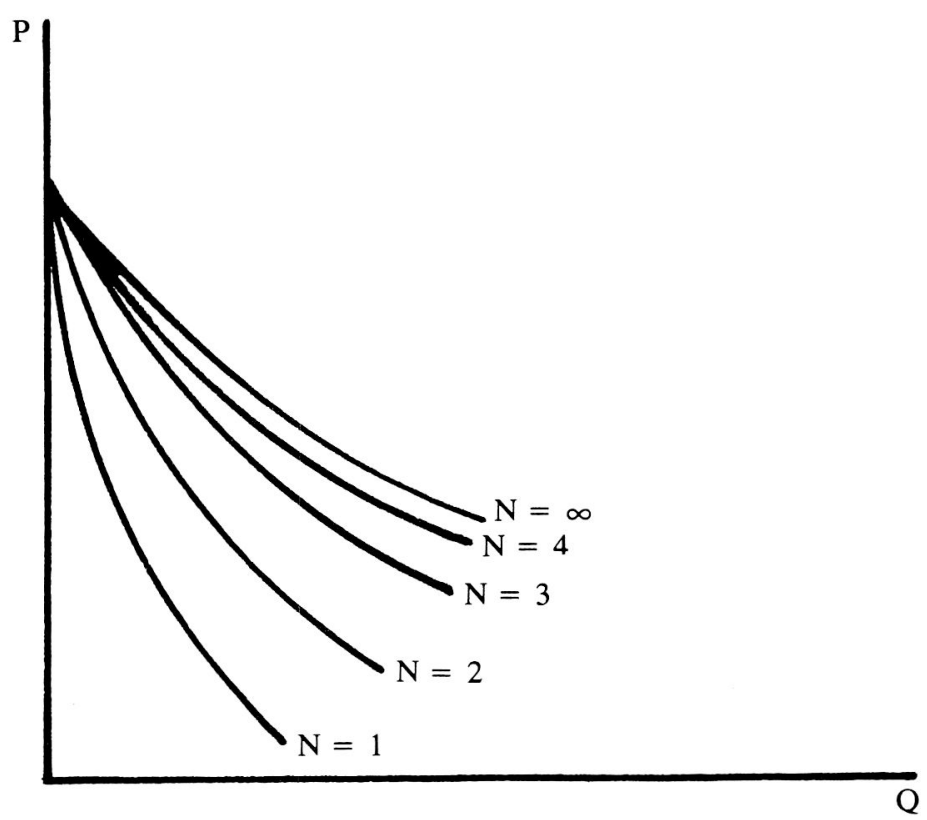

Figure 1-The Impact of Entry on Market Demand in Spatial Competition

tion, market demand rises as more firms enter. An increase in price is not counter-intuitive under such conditions.

Of course, the above discussion concerning the effect of entry on price is meant to intuitively align the spatial results with spaceless neoclassical price theory. The price determining factors are really quite different in spatial and spaceless competition. A large number of firms produce a product in spaceless competition, with price determined purely by the interaction of market supply and demand. Each price-taking firm faces a perfectly elastic demand curve. This is not the case in spatial competition. A large number of firms may produce a product but they are never price-takers. As long as distance is relevant (that is, as long as transport costs are positive) and both consumers and producers are geographically distributed, individual firms cannot have perfectly elastic demand [10].

Spatial competition actually consists of a linked oligopoly network even when a large number of firms are competing. Thus, spatial firms are interdependent price setters. Price is not determined by the interaction of market level supply and demand. Rather, price is determined by the entrepreneur, given his costs, his revenues, and his expectation of rival response to his pricing policies. ${ }^{6}$

If we begin with a single firm in a spaceless world and observed the effect of entry on the firm's demand curve, we find that it becomes increasingly elastic. Thus, the spaceless firm tends to lower price with entry. A spatial firm's de- 


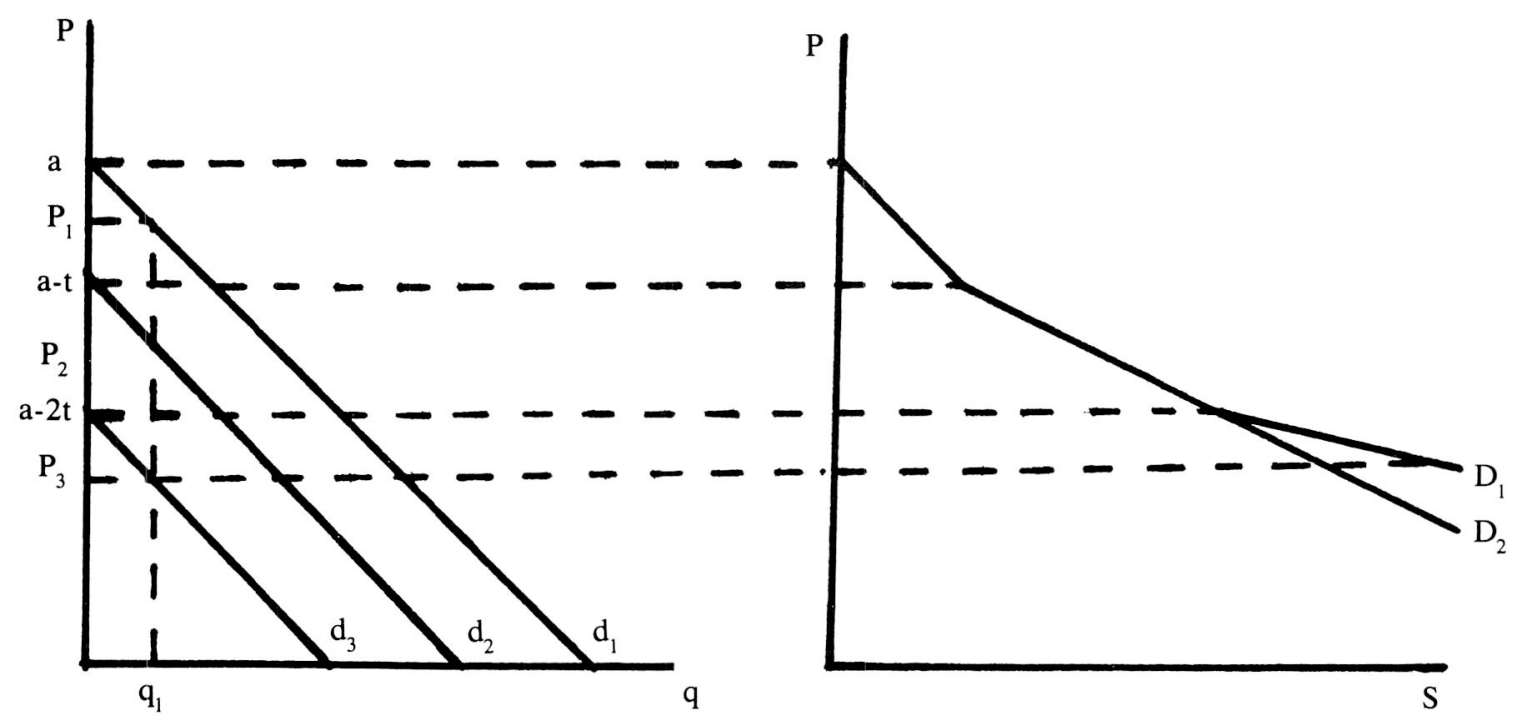

(i)

(ii)

Figure 2-The Impact of Distant Competition on a Firm's Demand

mand may be either more or less elastic following entry $[3,9,16]$. Consider, for example, Figure 2. Assume that three consumers have identical linear demand curves. In panel (i) of Figure 2, $d_{1}$ represents the effective demand of a consumer located at the firm's location. This same $d_{1}$ is the demand of the other two consumers before transport costs are netted out. Curve $d_{2}$ represents the net demand of a consumer located one distance unit away from the firm. This consumer pays transport costs $(a-t)$ per unit of purchase (where a is the price intercept of individual gross demand and $t$ is the transport rate per unit of distance). Curve $d_{3}$ represents net demand for a consumer located two distance units from the firm and paying $(a-2 t)$ in transport costs per unit of purchase. So, for example, all three consumers are willing to pay delivered price $P_{1}$ for $q_{1}$ units of output. However, the consumer with demand $d_{2}$ is willing to pay only $P_{2}$ to the firm since he must pay $(a-t)=\left(P_{1}-P_{2}\right)$ in transport costs. These net demands are the effective demands of relevance to the firm. Consumers can have identical tastes but different effective demands depending upon their location. Aggregate spatial demand is then the sum of the three net demands $\left(D_{1}\right.$ in panel (ii) of Figure 2$)$, and is concave upward [12]. (Aggregate demand for a spatial monopolist facing a continuous distribution of consumers is a smooth concave curve such as $D_{1}$ in Figure 3 [12].)

Now, what is the impact of distant competition on spatial aggregate demand? Assume profit maximizing price is $\mathrm{P}_{3}$ in Figure 2 so the monopolist is serving all three consumers. Now let a new firm enter. The impact of distant 


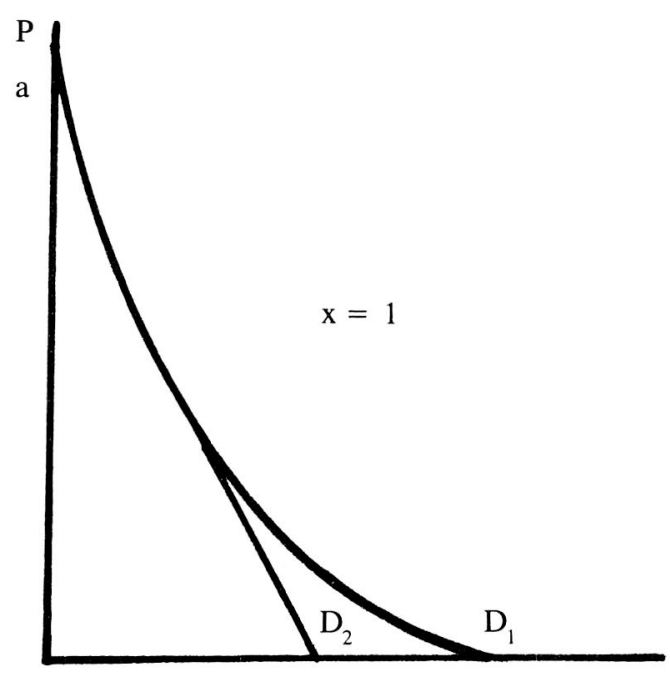

(i)

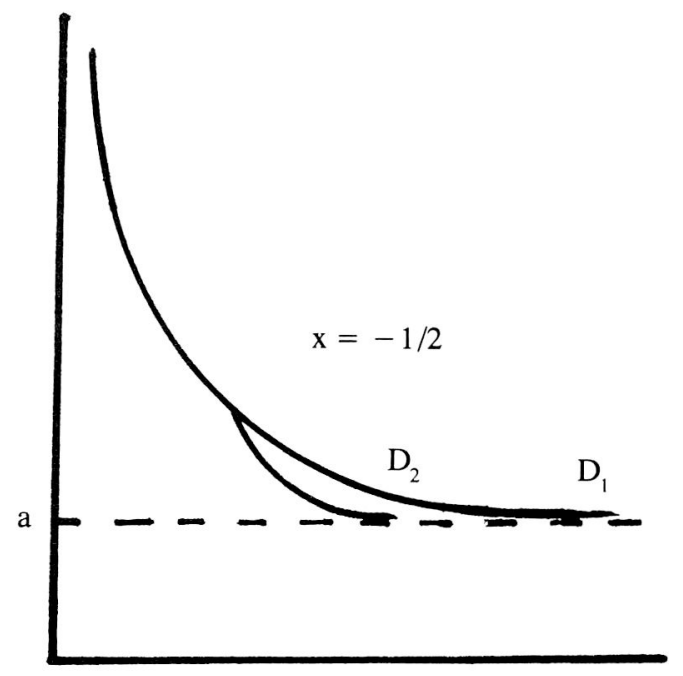

(ii)

Figure 3-The Impact of Distant Competition on a Firm's Demand When Consumers are Continuously Distributed

entry is that the monopolist loses his most distant consumers. Therefore let our firm lose demand $d_{3}$. His new aggregate demand is $D_{2}$. $D_{2}$ is less elastic at $P_{3}$ than is $\mathrm{D}_{1}$-the opposite of what occurs in spaceless competition. This occurs because the elasticity at any price (i.e., $\mathrm{P}_{3}$ ) increases when transport costs are subtracted from a linear (or positive exponential) demand to obtain net demand $[3,9,16]$. Therefore, the impact of entry of a new competitor at a distant point is to take away the most elastic demand. The aggregate demand left for the seller is less elastic than was the original demand. The resulting price effect is upward. Thus there are both intuitive and theoretical reasons for these socalled "perverse" results of Löschian competition. ${ }^{7}$

When costly distance is involved, intuition based upon standard spaceless neoclassical price theory is often wrong. ${ }^{8}$ The same change that has a very obvious single impact in a spaceless model (i.e., entry) may have more repercussions in a spatial setting. Therefore, results of spatial pricing models should not be labeled "perverse" when they differ from spaceless microeconomics.

\section{FOOTNOTES}

1 The model is referred to as Löschian competition since the basic assumptions were set forth by Lösch [14]. They were more rigorously developed in [15], and have since been widely used. This model involves adequate assumptions to establish market equilibrium conditions, including an assumption regarding entrepreneurial behavior. Each entrepreneur believes his market area is fixed and prices as a monopolist within that area. The so-called counter-intuitive results have been attributed to this behavioral assumption $|6,7,8|$ but they have since been shown to be dependent upon the assumption made concerning the shape of the individual demand function [3]. By altering the demand function assumptions made in 
$[6,7,8]$, all the counter-intuitive results are changed to those expected by the authors [3]

2 Specification of the shape of the individual demand and cost functions is sufficient to determine the price effect in a Löschian model.

3 See Greenhut and Ohta [12] for further discussion of this demand function.

4 We assume that following entry, firms are evenly dispersed over space, recognizing that this need not be the case under certain circumstances [13]. However, when $\mathrm{N}$ is greater than two and demand is highly elastic and/or freight charges are costly and/or marginal costs are high, an even dispersion of firms will result. See [2] for further discussion. We therefore will assume $\mathrm{N}$ is significantly larger than two and at least one of these other factors apply.

Note that an even distribution of identical consumers over a homogeneous linear market and an even spacing of firms with identical entrepreneurial behavior results in all firms charging an identical price $[1,7\}$. The Löschian model assumes identical behavior so price in equation (4) will be the same for all $\mathrm{N}$ firms.
5 All $\mathrm{N}$ firms charge an identical price given the assumptions of the Löschian model (see note 4 above).

6 See Greenhut for detailed elaboration of these arguments [10].

7 The behavioral assumption of Löschian competition (see note 1 above) implies that the firm recognizes his actual demand (i.e., $\mathrm{D}_{2}$ in Figure 2) rather than perceiving some other demand $[5,16]$. Consequently, entry need not lead to higher prices under Löschian competition. When demand is a negative exponential (i.e., $\mathrm{x}=-1 / 2$ in $\mathrm{P}+\mathrm{tu}=\mathrm{a}-\mathrm{bq}^{\mathrm{x}}$, or with $\mathrm{a}$ constant elasticity demand) the price effect of entry will be downward. This results because the elasticity at any price decreases as transport costs are subtracted from any gross demand with concavity given by $\mathrm{x}<0$ [3]. Distant competition removes the least elastic demands from a seller's market space. The remaining aggregate demand is then more elastic than was the original aggregate demand (as in Figure 3, panel (ii)). The price effect is downward.

8 See $[1,3,4,9]$ for discussion of some of the other implications of spatial competition which differ significantly from the conclusions of spaceless price theory.

\section{REFERENCES}

1. BENSON, B., "An Examination of U.S. v. Philadelphia National Bank in the Context of Spatial Microeconomics," Industrial Organization Review, 8:27-65 (December 1980).

2. , "Are the Conclusions of Löschian Spatial Competition Really Counter-Intuitive?," Working Paper, The Pennsylvania State University (April, 1980).

3._, "Löschian Competition Under Alternative Demand Conditions," American Economic Review, 70: 1098-1105 (December 1980).

4 , "Spatial Competition: Implications for Market Area Delineation in Antimerger Cases," The Antitrust Bulle'tin (25:729-744) (Winter, 1980).

5.__ "Spatial Microeconomics: Implications for the Use of Concentration Ratios to Represent Market Power," Review of Regional Studies, Vol. 9, No. 2 (Fall, 1979).

6. CAPOZZA, D. AND K. ATTARAN, "Pricing and Spatial Dispersion of Firms Under Free Entry," Journal of Regional Science, 16: 167-182 (August 1976).

7

AND R. VAN ORDER, "A American Economic Review, 68: 896-908 (December 1978).
8. AND . "A Simple Model of Spatial Pricing Under Free Entry," Southern Economic Journal, 44: 361-367 (October 1977).

9. GREENHUT, J., GREENHUT, M. AND KELLY, W., "A Spatial-Theoretical Perspective for Bank Merger Regulation," Proceedings of a Conference on Bank Structure and Competition, Federal Reserve Bank of Chicago, 210-253, (May, 1977).

10. GREENHUT, M. A Theory of the Firm in Economic Space. Austin: Austin Press, 1971.

11. , M. HWANG AND H. OHTA. "Observations on the Shape and Relevance of the Spatial Demand Function," Econometrica, 43: 705-713 (July 1975).

12. AND H. OHTA. Theory of Spatial Pricing and Market Areas. Durham: Duke University Press, 1975.

13. HOTELLING, H., "Stability on Competition," Economic Journal, 39: 41-57 (March 1929).

14. LÖSCH, A. The Economics of Location. New Haven: Yale University Press, 1954.

15. MILLS, E. AND LAV, R., "A Model of Market Area with Free Entry," Journal of Political Economy, 72: 278-288 (June 1964).

16. OHTA, H., "Spatial Competition, Concentration, and Welfare," Regional Science and Urban Economics, 10: 3-16 (March 1980). 